\title{
Learning Effects, Achievement Goals and Time \\ Constraints in Accounting Education: Findings from Experiments
}

\author{
Pi-Yueh Cheng (Corresponding author) \\ Dept. of Finance, Tainan University of Technology \\ No.529, Zhongzheng Rd., Yongkang District \\ Tainan 71002, Taiwan (R.O.C.) \\ Tel: 886-9-826-336_E-mail: t20030@mail.tut.edu.tw
}

\author{
Miao-Ling Fang \\ Dept. of Business Administration \\ Southern Taiwan University of Science and Technology \\ No. 1, Nan-Tai Street, Yongkang District \\ Tainan 71005, Taiwan
}

Tel: 886-6-2533131 ext. $4531 \quad$ Email: melody@mail.stust.edu.tw

Received: March 30, 2018 Accepted: May 15, 2018 Published: August 8, 2018

doi:10.5296/ire.v6i2.12868 URL: http://dx.doi.org/10.5296/ire.v6i2.12868

\begin{abstract}
Accounting education has been a topic of great concern to scholars, and teachers of accounting want to enhance students' learning performance. Thus, in this study, we conducted laboratory experiments to investigate how mastery/performance achievement goal orientations influence the accounting performance of students. Ninety undergraduates from Tainan Technology University participated in this study. The experiment examined how the type of student achievement goal and the test time influenced accounting performance. A two-way between-participants factorial design of achievement goal (mastery vs. performance) $\times$ test time (30 vs. 40 vs. $50 \mathrm{~min}$ ) was adopted. The results of students' score changes from
\end{abstract}


pre-test to post-test revealed that those students with a mastery achievement goal had a better learning effect than those with a performance achievement goal. The main effect of test time also showed a significant difference. The score change in the low-difficulty condition (longest time) was significantly higher than that in the moderate-difficulty condition (intermediate amount of time), and the score change in the moderate-difficulty condition was significantly higher than that in the high-difficulty condition (shortest time). Lastly, the two-way interaction of achievement goal type and test time was significant. The effect of test difficulty on score change was contingent on the type of achievement goal.

Keywords: achievement goal, learning effect, mastery goal, performance goal, test time

\section{Introduction}

Goal-setting theory posits that the learning goal has an incentive effect, which can turn a student's needs into motivation and bring a student's behavior into accordance with a planned direction (Cao \& Liu, 2011). Since the mid-1980s, many researchers have made attempts to study the differences between setting mastery goals (goals toward developing and gaining competence) and performance goals (goals toward demonstrating competence relative to others) (e.g., Belenky \& Nokes-Malach, 2012; Preenen, van Vianen, \& De Pater, 2014). Moreover, some studies have stated that, "Students with mastery orientation seek to improve their competence. Those with performance orientation seek to prove their competence." (Schraw, 1998, p. 122). Martin (2007) also indicated that mastery goals are more positively associated with educational aspirations, class participation, and enjoyment of school than performance goals. A possible reason for these differences is that mastery goals are closely aligned with intrinsic motivation and, thus, are deemed directly relevant to a framework articulating motivation and engagement (Brophy, 2005). Previous research has indicated that one of the main differences between mastery goals and performance goals is the standard by which competence is defined (Darnon, Dompnier, Gilliéron, \& Butera, 2010). In accordance with this idea, many research results have also suggested that social comparison is a more important concern when pursing performance goals than when pursuing mastery goals (Ames, 1992; Butler, 2005; Kaplan \& Maehr, 2007).

Additionally, many previous studies have focused on time constraint issues. For example, Benson and Beach (1996) investigated whether the effects of time constraints on screening are similar to those that have been reported for choice. Ackerman and Lauterman (2012) examined the effects of time pressure on learning texts on a screen relative to paper among undergraduates who reported only a moderate preference for paper. Chuderski (2016) investigated the different effect of prior experience with and without time pressure. Ordóñez and Benson (1997) argued that decision-makers use the same strategies when making risky decisions with and without a time constraint. Chiou and Wan (2007) determined the time constraints for search tasks used in subsequent experiments focused on searching out information on the Internet. In summary, working under time pressure has been suggested to have two consequences. On the one hand, awareness of time constraints may distract learners from the task at hand and so reduce their working memory resources (Dunlosky \& Thiede, 2004). On the other hand, mild time pressure can help learners' motivation to excel, and clear 
action implications can improve their study efficiency through disengagement from failing courses of action (Henderson, Gollwitzer, \& Oettingen, 2007).

However, little research has examined the learning effect of achievement goals under time constraints in the student learning outcomes of an accounting course. In the current study, we aimed to provide a further test of the hypothesis that mastery achievement goal orientations lead to a better learning effect than performance achievement goal orientations under time constraints.

\section{Overview of the Current Research}

A laboratory experiment was conducted to examine whether mastery/performance achievement goals under time constraints influence the accounting performance of accounting students. Before the actual study, it was necessary to conduct a pre-experiment to confirm the independent variable, i.e., to examine the achievement goal and time constraints, experimental manipulation effect, and whether the research expectation was sound. The formal experiment tested whether the type of student achievement goal and the test time influenced accounting performance.

\subsection{Pre-test: Establishment and Validation of Achievement Goal Manipulation Paradigm}

\subsubsection{Participants and Design}

Fifty-one undergraduates $(\mathrm{M}=18.9$ years old, $\mathrm{SD}=0.8$ years; $65 \%$ female $)$ from Tainan Technology University of Taiwan participated in the pre-test in exchange for course credit in their Introduction to Accounting course. This study was approved by the Institutional Review Board of Tainan Technology University. The pre-test followed the study of Harackiewicz and Elliot (1993) and was designed to investigate the effects of achievement goals on an enjoyable activity, i.e., pinball (4 weeks). After subjects were assigned by a block-random method, they received either a performance, mastery, or neutral goal manipulation. All subjects self-reported by finishing a questionnaire that measured their achievement goals.

\subsubsection{Procedure}

On arrival in the experimental laboratory, participants were introduced to the game and concept of pinball. They were verbally given a particular goal manipulation. The subjects receiving a performance goal were told the following:

What we are interested in is how well some students play pinball compared to others. We're assembling students with different levels of pinball experience and collecting data on how they play compared to others.

Subjects assigned a mastery goal were instructed as follows:

What we are interested in is how students develop their pinball skills on our pinball machines. We're assembling students with different levels of pinball experience and collecting data on how they learn to play and improve on our Jungle King machine.

Control subjects were told the following: 
What we are interested in is students' reactions to games and leisure activities. We're assembling students with different levels of pinball experience and collecting data on what they think of our pinball machine.

Then, all participants were required to finish a 12-item, self-reported achievement goal questionnaire (AGQ; Elliot \& McGregor, 2001) with a 7-point Likert scale (the Cronbach alpha values of mastery goal and performance goal orientations were 0.907 and 0.886 , respectively).

\subsubsection{Results of Pre-test}

Analyses were based on the following criteria for judging the effectiveness of achievement goal manipulation. First, an evaluation of the interaction of achievement goal-type score and achievement goal manipulation was obtained. Second, in subsequent planned contrasts, the felt mastery goal should be significantly higher in the induced mastery goal condition than in the performance goal and the control conditions, while the felt performance goal should be significantly higher in the induced performance goal condition than in the mastery goal and control conditions.

The first criteria for the success or failure of the manipulation, the felt mastery and performance goal scores (See Table 1), were submitted to a 2 (type of score) $\times 3$ (achievement goal manipulation) mixed ANOVA, which treated the type of achievement goal score (felt mastery goal or felt performance goal) as a repeated factor and the achievement goal manipulation (mastery goal, performance goal, or control) as a between-subjects factor. The analysis showed that the two-way interaction was significant $(\mathrm{F}(2,48)=79.69, \mathrm{p}<.01)$, indicating that different types of achievement goal manipulation could induce different types of felt achievement goal. The second criteria for the success or failure of the manipulation was a test of the average score of the achievement goal group for a mastery goal or a performance goal, respectively. Follow-up contrasts with Dunn's multiple comparison procedure were suitable for these comparisons (Kirk, 2012). The control of error rate was used to obtain a solid examination of manipulation check. Therefore, the type I error of this experiment was set as 0.05 . Each of these two contrasts was distributed with a value of 0.025 . In terms of a felt achievement mastery goal, the main effect of the achievement goal manipulation was significant $(\mathrm{F}(2,48)=9.95, \mathrm{p}<.01)$, showing that attainment of a felt achievement mastery goal was significantly different among the three manipulation conditions.

As Levene's test for homogeneity of variances revealed that equal variance of felt mastery goal among the three conditions was supported $(\mathrm{F}(2,48)=4.25$, ns.), equal variance was assumed for the subsequent contrasts. Planned contrast analyses showed that the prevalence of the mastery goal orientation was significantly higher in the mastery goal-induced condition $(\mathrm{M}$ mastery $=5.46)$ than in the other two conditions ( $\mathrm{M}$ performance $=3.73, \mathrm{M}$ control $=$ 3.63 ), with $\mathrm{t}(48)=8.79$ and $\mathrm{t}(48)=9.92$ for the two contrasts, respectively (two ps $<0.025$ ). In terms of felt achievement performance goal, the main effect of the achievement goal manipulation was significant $(\mathrm{F}(2,48)=9.95, \mathrm{p}<.01)$, showing that the felt achievement performance goal was significantly different among the three manipulation conditions. 
Because Levene's test for homogeneity of variances revealed that equal variance of felt performance goal among the three conditions was supported $(\mathrm{F}(2,48)=1.25$, ns.), equal variance was assumed for the subsequent contrasts. Planned contrast analyses showed that performance goal orientation was significantly higher in the performance goal-induced condition $(\mathrm{M}$ performance $=5.79)$ than in the other two conditions $(\mathrm{M}$ mastery $=3.77 \mathrm{M}$ control $=3.94$ ), with $\mathrm{t}(48)=8.65$ and $\mathrm{t}(48)=9.39$ for the two contrasts, respectively (two ps $<0.025)$. The results confirmed that the manipulation of achievement goal was successful in the pre-test.

Table 1. Descriptive Statistics of Achievement Goal Type of Score by Achievement Goal Manipulation

\begin{tabular}{lcccccc}
\hline & \multicolumn{6}{c}{ Achievement goal manipulation } \\
\cline { 2 - 7 } Achievement goal score & Mastery condition & Performance condition & \multicolumn{2}{c}{ Control condition } \\
& M & SD & M & SD & M & SD \\
\hline Mastery Goal & 5.46 & 0.82 & 3.73 & 0.48 & 3.63 & 0.39 \\
Performance Goal & 3.77 & 0.57 & 5.79 & 0.59 & 3.94 & 0.76 \\
\hline
\end{tabular}

Note. $\mathrm{N}=17$ participants in each of the achievement goal manipulation, self-reported achievement goal were rated on a 7-point score.

\subsection{Formal Experiment: Exposure to Student Achievement Goal and Test Time Influences on Accounting Performance}

This experiment aimed to examine how the type of student achievement goal and test time influenced accounting performance. After the achievement goal manipulation (mastery, performance), participants were asked to complete an accounting pre-test within $50 \mathrm{~min}$, a series of pinball games (achievement goal manipulation for 4 weeks), a 12-item achievement goal questionnaire, and an accounting post-test with determined time constraints. The experiment adopted the method of Chiou and Wan (2007) and used the time period as a manipulation of task difficulty. There were three test time periods (i.e., 30, 40, and $50 \mathrm{~min}$ ), corresponding to low, medium, and high difficulty.

\subsubsection{Participants and Design}

Ninety undergraduates $(\mathrm{M}=19.1$ years old, $\mathrm{SD}=0.8$ years; $62 \%$ female $)$ attending a university in southern Taiwan participated in this experiment for extra course credit. This study had a 2 (achievement goal: mastery vs. performance) $\times 3$ (test time: 30 vs. 40 vs. 50 min) between-subjects design. Participants were randomly assigned to one of the six conditions, and each condition had 15 participants. Materials that contained a pre-test, pinball game, questionnaire, post-test, and demographic sheet were presented.

\subsubsection{Procedures}

First, all participants were asked to finish a pre-test within $50 \mathrm{~min}$. The test consisted of 50 multiple-choice items on accounting that were selected randomly from the test bank created 
by the Workforce Development Agency of the Ministry of Labor in Taiwan. Second, the achievement goal manipulation procedure taking 4 weeks (mastery goal and performance goal) was identical to that of the pre-test. Third, all participants were then asked to complete a 12-item, self-reported achievement goal questionnaire (AGQ; Elliot \& McGregor, 2001) based on a 7-point Likert scale (the Cronbach alpha values of mastery goal and performance goal were 0.899 and 0.856 , respectively). Finally, all participants were asked to complete a post-test containing an isomorphic version of the pre-test problems, with one-third of the participants having $30 \mathrm{~min}$, one-third having $40 \mathrm{~min}$, and the remaining one-third having 50 $\min$.

\subsubsection{Test Materials}

The pre-test and post-test materials consisted of an accounting practice achievement test of 50 multiple-choice items. The test materials were selected randomly from the test bank created by the Workforce Development Agency of the Ministry of Labor in Taiwan. The post-test was an isomorphic version of the pre-test problems.

\subsubsection{Manipulation Check}

To confirm the success of the achievement goal manipulation, the achievement goal type was taken as the independent variable, and the achievement goal score was taken as the dependent variable. A t-test verified that the mastery achievement goal score was higher than the performance achievement goal score for the mastery achievement goal group and that the performance achievement goal score was higher than the mastery achievement goal score for the performance achievement goal group. The control of error rate was used to obtain a solid examination of the manipulation check. The type I error of this experiment was set as 0.05 , and each of the two contrasts was distributed with a value of 0.025 . Planned contrast analyses showed that mastery goal orientation was significantly higher in the mastery goal-induced condition $(\mathrm{M}$ mastery $=5.91)$ than in the performance goal-induced condition $(\mathrm{M}$ performance $=3.05)$, with $\mathrm{t}(88)=18.79(\mathrm{p}<.025)$. The results also showed that performance goal orientation was significantly higher in the performance goal-induced condition (M performance $=6.22$ ) than in the mastery goal-induced condition ( $\mathrm{M}$ mastery $=2.61)$, with $t(88)=22.76(p<.025)$. The results confirmed that the manipulation of achievement goal in the experiment was successful.

With respect to the validation of this post-test, data from a follow-up examination $(\mathrm{N}=90)$ supported the method used as appropriate for manipulation of test difficulty. We randomly assigned participants to each of the three levels of test difficulty determined by the test time allowed and asked them to finish the post-test quiz under the different time constraints. Additionally, a linear trend analysis was conducted to examine the influence of test time, reflecting the different degrees of test difficulty, on participants' cognition, and the results showed that a higher time period predicted students finishing the post-test with a higher score $(\mathrm{F}(1,87)=170.55, \mathrm{p}<.001)$. Follow-up contrasts showed that participants in the low-difficulty group $(\mathrm{M}=83.67)$ obtained higher post-test scores than participants in the moderate-difficulty group $(\mathrm{M}=72.77), \mathrm{t}(87)=5.41, \mathrm{p}<.01$, and that participants in the moderate-difficulty group attained higher post-test scores than those in the high-difficulty 
group $(\mathrm{M}=67.03), \mathrm{t}(87)=3.21, \mathrm{p}<.05$. Thus, the manipulation of the test time variable was effective.

\section{Results}

This experiment adopted achievement goal (mastery vs. performance) and test time (30 vs. 40 vs. $50 \mathrm{~min}$ ) as independent variables and the change of score between the post-test and the pre-test as the dependent variable. The current experiments used a two-way ANOVA between-subjects design and explored the interaction between achievement goal and test time for score change.

A statistical summary of participants' test scores, including pre-test, post-test, difference of post-test and pre-test, and adjusted difference of post-test and pretest, is presented in Table 2. First, the six groups differed significantly from one another in pre-test scores, $F(5,84)=4.95$, $\mathrm{p}<.05$, indicating that the pre-test scores would be a confounding variable in the follow-up study. Second, an examination using the Levene's test for homogeneity of variances revealed that unequal variance among the six conditions was supported $(\mathrm{F}(5,84)=1.57$, ns.); equal variance was assumed for the subsequent contrasts.

Table 2. Means and Standard deviations of the scores in experiment 1

\begin{tabular}{|c|c|c|c|c|c|c|c|c|c|c|c|c|}
\hline \multirow{4}{*}{$\begin{array}{l}\text { Score } \\
\text { measure }\end{array}$} & \multicolumn{12}{|c|}{ Achievement goal } \\
\hline & \multicolumn{6}{|c|}{ Mastery goal } & \multicolumn{6}{|c|}{ Performance goal } \\
\hline & \multicolumn{2}{|c|}{ High } & \multicolumn{2}{|c|}{ Moderate } & \multicolumn{2}{|c|}{ Low } & \multicolumn{2}{|c|}{ High } & \multicolumn{2}{|c|}{ Moderate } & \multicolumn{2}{|c|}{ Low } \\
\hline & Mean & SD & Mean & SD & Mean & SD & Mean & SD & Mean & SD & Mean & SD \\
\hline Score at & 57.67 & 10.9 & 53.4 & 12.1 & 52.3 & 10.1 & 63.0 & 2.2 & 69.0 & 4.1 & 75.4 & 11.2 \\
\hline Score at & 68.40 & 2.85 & 75.2 & 3.94 & 87.5 & 2.75 & 66.1 & 2.9 & 70.8 & 3.3 & 79.8 & 7.17 \\
\hline Score & 10.73 & 10.6 & 21.8 & 11.99 & 35.2 & 10.4 & 3.13 & 2.9 & 1.80 & 2.2 & 4.33 & 7.54 \\
\hline Score & 7.08 & 0.94 & 14.3 & 1.06 & 25.8 & 1.17 & 3.76 & 0.9 & 4.96 & 1.2 & 12.1 & 1.33 \\
\hline
\end{tabular}

Note: 1. Each cell 15 participants.

2. *The difference mean adjusted by Covariance of pretest.

Third, the pre-test was a confounding variable. Thus, subsequent analyses adopted the ANCOVA and the pre-test as the covariate variable. The interaction between the covariate variable (pre-test) and the achievement type was significant $(\mathrm{F}(1,80)=22.35, \mathrm{p}<.01, \quad=$ 0.22 ), and the interaction between the covariate variable (pre-test) and the task difficulty was not significant $(\mathrm{F}(2,80)=0.37$, ns., $=0.01)$. Thus, the linear relationship between the independent variable (achievement type) and the covariate variable (pre-test) reveled non-consistency, and the linear relationship between the independent variable (task difficulty) and the covariate variable (pre-test) reveled consistency. As shown in Table 2, the six-level differences of post-test and pre-test were 10.73, 21.87, 35.20, 3.13, 1.80, and 4.33. The differences adjusted by the covariance variable (pre-test) between post-test and pre-test were 


\section{Macrothink}

$7.08,14.31,25.87,3.76,4.96$, and 12.14. Fourth, the two-way interaction between achievement goal type and test time was significant $(F(6,80)=184.29, \mathrm{p}<.01, \quad=0.93)$, and the effect of test difficulty on the score change was contingent on the type of achievement goal, as illustrated by Figure 1 .

Lastly, the main effect of achievement goal type was significantly different $(F(1,80)=80.54$, $\mathrm{p}<.01,=0.50)$, showing that the adjusted score change in the mastery goal-induced condition $(\mathrm{M}=15.75)$ was significantly higher than that of the performance goal-induced condition $(\mathrm{M}=6.95)$. The main effect of task difficulty was also significantly different $(\mathrm{F}(2$, $80)=96.64, p<.01, \quad=0.50)$, showing that the adjusted score change in the low-difficulty condition ( $\mathrm{M}=19.01)$ was significantly higher than that the moderate-difficulty condition $(\mathrm{M}$ $=9.63$ ) and that the adjusted score change in the moderate-difficulty condition was significantly higher than that in the high-difficulty condition $(\mathrm{M}=5.42)$.

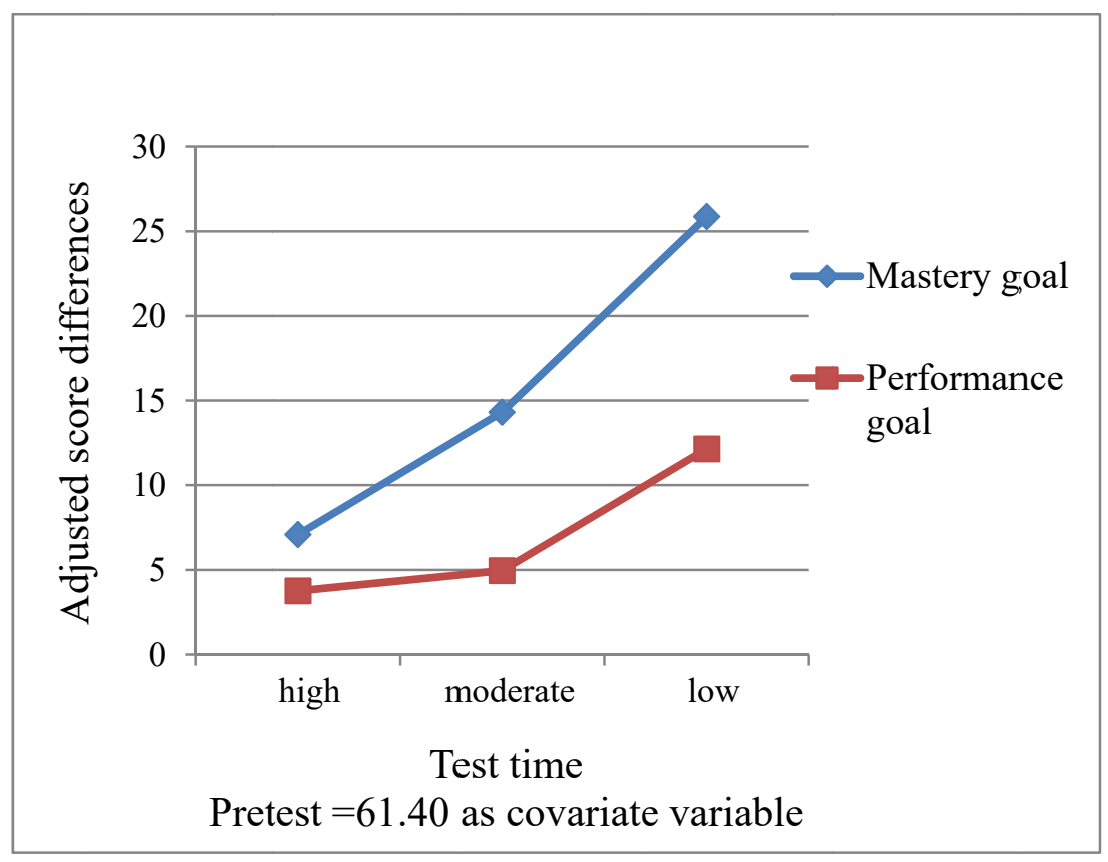

Figure 1. Interaction of achievement goal type and task difficulty

\section{Discussion}

The purpose of this research was to explore whether mastery achievement goal orientation leads to a better learning effect than performance achievement goal orientation under time constraints. Based on the findings of this research, the following conclusions can be stated. First, as expected, this research indicated that the learning effect results (score change) revealed interaction with different task difficulty levels (low vs. moderate vs. high) with respect to different goal type (mastery vs. performance). Second, we found that when the level of task difficulty was high, the accounting score change of the mastery goal group was better than that of the performance goal group. This finding is consistent with the research of Zhang, Wang, and Adesope (2016) on learning English-language words. It is possible that the mastery goal orientation is closely related to students' sense of self-improvement and growth. 
This finding can also explain the task-difficulty results for learners during their accounting course under different goal types (Elliot, 1999; Pintrich, 2000). Finally, we found that students in the easy task situation had greater score changes. This finding is consistent with numerous studies that have demonstrated the importance of self-efficacy for the success of students in general academic and practice settings (Bong \& Skaalvik, 2003). Consistent with the general definition of self-efficacy, academic self-efficacy refers to a student's own perception of his or her competence with respect to classwork (Midgley et al., 2000).

In conclusion, the results of the current study provide three crucial educational implications that educators may wish to consider. Firstly, there is the finding that mastery goal orientation leads to better learning performance than performance goal orientation. Thus, teachers should make efforts to facilitate a "learning to learn" attitude to improve students" ability, and thereby encourage them not to compare themselves with other students in an undergraduate course (e.g., Chen, Hsu, \& Chen, 2013). Secondly, because the interaction between goal type and task difficulty showed a significant result, attention should be paid to assessing different goal types to set an appropriate goal type based on different task difficulties. Finally, the main effect of task difficulty was significantly different, showing a score change order of low difficulty, moderate difficulty, and high difficulty, respectively. Because task difficulty is an antecedent of self-efficacy, which has been studied widely in psychology with a view to understanding and predicting human behavior (Gore, 2006), teachers should try to enhance students' self-efficacy in their learning process.

It should be noted that the present research has some limitations. Firstly, the research design adopted only two goal types. Therefore, future study adding the goal valence dimension to the theory would allow both mastery and performance goals to be framed in either an approach or an avoidance manner (e.g., Madjar, Kaplan, \& Weinstock, 2011; Roussel, Elliot, Feltman, 2011; Senko \& Hulleman, 2013). Secondly, there are confounding variables in students' learning processes, for example, students' perceptions of level of interest for learning (Harackiewicz \& Hulleman, 2010; Harackiewicz, Durik, Barron, Linnernbrick-Garcia, \& Tauer, 2008) and students' perceptions of course importance (Hall, Pierce, Tunnell, \& Walther, 2014), that influence students' learning effects. Thus, further research may consider these two variables as moderate variables when investigating student learning effects. Thirdly, the current research ignored the method of teacher transfer of knowledge. A common goal of the cognitive and educational domain invollves the question of how students learn new concepts and how knowledge is transferred (Belenky \& Nokes-Malach, 2013; Bransford \& Schwartz, 1999; Cheng, Schultz, \& Booth, 2009; Lobato, 2006). Colburn (2000) indicated that there are two learning processes for students: "invention" activity, in which students first attempt to invent the necessary procedures for a task, resulted in increased task-based goals compared to the more standard form of direct instruction, called "tell-and-practice", in which students are first shown a method for solving a type of problem and then given an opportunity to practice with a new problem. Further research may benefit from examining how students' perceptions of the teacher transfer of knowledge method influence the student learning effect. Finally, the present research targeted only participants in an accounting course. It is suggested that further research study a different course, with this 
research design, to examine learning effects in other disciplines.

\section{Acknowledgements}

The author would like to dedicate his greatest gratitude to the Ministry of Science and Technology, Taiwan for the financial support (103-2511-S-165-003-MY3).

\section{Reference}

Ackerman, R., \& Lauterman, T. (2012). Taking reading comprehension exams on screen or on paper? A metacognitive analysis of learning texts under time pressure. Computers in Human Behavior, 28(5), 1816-1828. https://doi.org/10.1016/j.chb.2012.04.023

Ames, C. (1992). Classrooms: Goals, structures, and student motivation. Journal of Educational Psychology, 84, 261-271. http://dx.doi.org/10.1037/0022-0663.84.3.261

Belenky, D. M., \& Nokes-Malach, D. J. (2012). Motivation and transfer: The role of mastery-approach goals in preparation for future learning. The Journal of the Learning Sciences, 21, 399-432. http://dx.doi.org/10.1080/10508406.2011.651232

Belenky, D. M., \& Nokes-Malach, D. J. (2013). Mastery-approach goals and knowledge transfer: An investigation into the effects of task structure and framing instructions. Learning and Individual Differences, 25, 21-34. http://dx.doi.org/10.1016/j.lindif.2013.02.004

Benson, L. III, \& Beach, O. (1996). The effects of time constraints on the pre-choice screening of decision options. Organizational Behavior and Human Decision Processes, 67, 222-228. http://dx.doi.org/10.1006/obhd.1996.0075

Bong, M., \& Skaalvik, E. (2003). Academic motivation in self-efficacy: How different are they really? Educational Psychological Review, 15, 1-40. http://dx.doi.org/10.1016/j.mattod.2016.07.013

Bransford, J. D., \& Schwartz, D. L. (1999). Rethinking transfer: A simple proposal with multiple implications. Review of Research in Education, 24, 61-100. http://dx.doi.org/10.2307/1167267

Brophy, J. (2005). Goal theorists should be move on from performance goals. Educational Psychologists, 40, 167-176. http://dx.doi.org/10.1207/s15326985ep4003_3i

Butler, R. (2005). Competence assessment, competence, and motivation between early and middle childhood. In A. J. Elliot \& C. S. Dweck (Eds.), Handbook of competence and motivation (pp. 202-221). New York, NY: Guilford Press.

Cao, R., \& Liu, P. (2011). A research on how goal-setting affects the score of working memory. Journal of Psychological Science, 34, 332-336.

Chen, B. H., Hsu, M. S., \& Chen, M. H. (2013). The relationship between learning attitude and anxiety in accounting classes: The case of hospitality management university students in Taiwan. Quality \& Quantity, 47, 2815-27. http://dx.doi.org/10.1007/s11135-012-9691-6

Cheng, M. M., Schultz, A. K. D., \& Booth, P. (2009). Knowledge transfer in project reviews: 
The effect of self-justification bias and moral hazard. Accounting \& Finance, 49, 75-93. http://dx.doi.org/10.1111/j.1467-629X.2008.00271.x

Chiou, W. B., \& Wan, C. S. (2007). The dynamic change of self-efficacy in information searching on the Internet: Influence of valence of experience and prior self-efficacy. The Journal of Psychology, 141, 598-603. http://dx.doi.org/10.3200/JRLP.141.6.589-604

Chuderski, A. (2016). Time pressure prevents relational learning. Learning and Individual Differences, 49, 361-365. http://dx.doi.org/10.1016/j.lindif.2016.07.006

Colburn, A. (2000). Inquiring scientists want to know. Educational Leadership, 62(1), 63-66.

Darnon, C., Dompnier, B., Gilliéron, O., \& Butera, F. (2010). The interplay of mastery and performance goals in social comparison: A multiple-goal perspective. Journal of Educational Psychology, 102, 212-222. http://dx.doi.org/10.1037/a0018161

Dunlosky, J., \& Thiede, K. W. (2004). Causes and constraints of shift-to-easier-materials effects in the control study. Memory and Cognition, 32, 779-788. http://dx.doi.org/10.3758/BF03195868

Elliot, A. J. (1999). Approach and avoidance motivation and achievement goals. Educational Psychologist, 34, 169-189. http://dx.doi.org/10.1207/s15326985ep3403_3

Elliot, A. J., \& McGregor, H. (2001). A $2 \times 2$ achievement goal framework. Journal of $\begin{array}{lllll}\text { Personality } \quad \text { and } & \text { Social sychology, } & 80, & \text { 501-519. }\end{array}$ http://dx.doi.org/10.1037/0022-3514.80.3.501

Gore, P. (2006). Academic self-efficacy as a predictor of college outcomes: Two incremental validity studies. Journal of Career Assessment, 14, 92-115. http://dx.doi.org/10.1177/1069072705281367

Hall, T. W., Pierce, B. J., Tunnell, P. L., \&Walther, L. M. (2014). Heterogeneous student perceptions of accounting course importance and their implications for SET reporting and use. Journal of Accounting Education, 32, 1-15. http://dx.doi.org/10.1016/j.jaccedu.2014.01.001

Harackiewicz, J. M., Durik, A. M., Barron, K. E., Linnernbrick-Garcia, L., \& Tauer, J. M. (2008). The role of achievement goals in the development of interest: Reciprocal relations between achievement goals, interest, and performance. Journal of Educational Psychology, 100, 105-122. http://dx.doi.org/10.1037/0022-0663.100.1.105

Harackiewicz, J. M., \& Elliot, A. J. (1993). Achievement goals and intrinsic motivation. Journal of Personality and Social Psychology, 65, 904-915.

Harackiewicz, J. M., \& Hulleman, C. S. (2010). The importance of interest: The role of achievement goals and task values in promoting the development of interest. Social and $\begin{array}{llll}\text { Personality Psychology } & \text { Compass, } & 42-52 .\end{array}$ http://dx.doi.org/10.1111/j.1751-9004.2009.00207.x

Henderson, M. D., Gollwitzer, P. M., \& Oettingen, G. (2007). Implementation intentions and disengagement from a failing courses of action. Journal of Behavioral Decision Making, 20, 
81-102. http://dx.doi.org/10.1002/bdm.553

Kaplan, A., \& Maehr, M. L. (2007). The contributions and prospects of goal orientation theory. Educational Psychology Review, 19, 141-184. http://dx.doi.org/10.1007/s10648-006-9012-5

Kirk, R. E. (2012). Experimental design: Procedures for the behavioral sciences (4th ed.). Thousand Oaks, CA: Sage.

Lobato, J. (2006). Alternative perspectives on the transfer of learning: History issues, challenges for future research. The Journal of the Learning Science, 15, 431-499. http://dx.doi.org/10.1207/s15327809jls1504_1

Madjar, N., Kaplan, A., \& Weinstock, M. (2011). Clarifying mastery-avoidance goals in high school: Distinguishing between intrapersonal and task-based standards of competence. $\begin{array}{llll}\text { Contemporary } \quad \text { Educational } & \text { Psychology, } & 36, & \text { 268-279. }\end{array}$ http://dx.doi.org/10.1016/j.cedpsych.2011.03.003

Martin, A. J. (2007). Examining a multidimensional model of student motivation and engagement using a construct validation approach. British Journal of Educational Psychology, 77, 413-440. http://dx.doi.org/10.1348/000709906X118036

Midgley, C., Maehr, M. L., Hruda, L. Z., Anderman, E., Anderman, L. \& Freeman. K. E. et al. (2000). Manual for the patterns of adaptive learning scales. Ann Arbor, MI: University of Michigan.

Ordóñez, L., \& Benson, L. III (1997). Decisions under pressure: How time constraint affects risky decision making. Organizational Behavior and Human Decision Processes, 71, 121-140. http://dx.doi.org/10.1006/obhd.1997.2717

Preenen, P. T. Y., van Vianen, A. E. M., \& De Pater, I. E. (2014). Challenging assignments and activation mood: The influence of goal orientation. Journal of Applied Psychology, 44, 650-659. http://dx.doi.org/10.1111/jasp.12256

Pintrich, P. (2000). An achievement goal theory perspective on issues in motivation terminology, theory, and research. Contemporary Educational Psychology, 25, 92-104. http://dx.doi.org/10.1006/ceps.1999.1017

Roussel, P., Elliot, A. J., Feltman, R. (2011). The influence of achievement goals and social goals on help-seeking from peers in an academic context. Learning and Instruction, 21, 394-402. http://dx.doi.org/10.1016/j.learninstruc.2010.05.003

Schraw, G. (1998). Promoting general metacognitive awareness. Instructional Science, 26, 113-125. https://doi.org/10.1023/A:1003044231033

Senko, C., \& Hulleman, C. S. (2013). The role of goal attainment expectancies in achievement goal pursuit. Journal of Educational Psychology, 105, 504-521. http://dx.doi.org/10.1037/a0031136

Zhang, P., Wang, Z., \& Adesope, O. (2016). The effects of goal type, learning interest, and 


\section{Macrothink}

International Research in Education

ISSN 2327-5499

2018, Vol. 6, No. 2

task difficulty on learning English words. International Journal of Learming, Teaching and Educational Research, 15, 32-46.

\section{Copyright Disclaimer}

Copyright reserved by the authors.

This article is an open-access article distributed under the terms and conditions of the Creative Commons Attribution license (http://creativecommons.org/licenses/by/3.0/). 